\section{Exceptionality Education International: Responding to Change and Promoting Dialogue on Inclusive Education for All}

\author{
Gabrielle Young \\ Memorial University \\ Jenn de Lugt \\ University of Regina \\ Sharon Penney \\ Memorial University \\ Jacqueline Specht \\ Western University
}

Scholarly and Research

Communication

VOLUME 10 / ISSUE 2 / 2019

\begin{abstract}
Exceptionality Education International (EEI) provides a forum for research and dialogue on topics relevant to the education of people with exceptionalities and on how barriers to the full participation of all people in education can be reduced and removed. As current editors of this journal, we provide you with an overview of the editorship of the journal over the years, address changes to policies and practices in inclusive education, and explain how our journal has adapted to reflect these changes. We conclude with concerns currently being experienced by journals, and plans for moving forward with addressing these issues and maintaining a journal in the $21^{\text {st }}$ century.
\end{abstract}

Keywords Academic journals; Dialogue; Exceptionalities; Inclusive education; Journal editorship

\section{Résumé}

Exceptionality Education International (EEI) fournit un espace pour la recherche et le dialogue sur des sujets relatifs à l'éducation de personnes comportant des « exceptionalités » et sur la réduction et l'élimination d’obstacles empêchant à quiconque de participer pleinement en éducation. À titre de directeurs, nous vous présentons un survol de la direction de cette revue au fil des années, traitons de changements aux politiques et pratiques en éducation inclusive, et expliquons comment notre revue s'est adaptée pour refléter ces changements. Pour conclure, nous
Gabrielle Young is an Associate Professor in the Faculty of Education at Memorial University. Gabrielle's research interests surround the use of assistive and instructional technology in inclusive classrooms, universal design for learning, and pre-service teachers' efficacy to support students with exceptionalities and facilitate positive mental health. Email: gabrielle.young @mun.ca

Jenn de Lugt is an Associate Professor in Inclusive Education at the University of Regina. Keenly aware of the important role mental health plays in all of our lives, her passion in both research and teaching relates to supporting the mental health of all learners in elementary and secondary schools. Email: Jenn.deLugt@uregina.ca

\title{
CISP Press
}

Scholarly and Research Communication

Volume 10, Issue 2, Article ID 1001307, 8 pages

Journal URL: www.src-online.ca http://doi.org/10.22230/src.2019v10n2a307

Received September 8, 2018, Accepted January 17, 2019, Published March 5, 2019

Young, Gabrielle, de Lugt, Jenn, Penny, Sharon, Specht, Jacqueline. (2019). Exceptionality Education International: Responding to Change and Promoting Dialogue on Inclusive Education for All. Scholarly and Research Communication, 10(2): 1001307, 8 pp.

(C) 2019 Gabrielle Young, Jenn de Lugt, Sharon Penney, Jacqueline Specht. This Open Access article is distributed under the terms of the Creative Commons Attribution Non-Commercial License (http://creativecommons.org/licenses/by-nc-nd/2.5/ca), which permits unrestricted non-commercial use, distribution, and reproduction in any medium, provided the original work is properly cited. 


\section{Scholarly and Research}

\section{Communication}

VOLUME 10 / ISSUE 2 / 2019

Sharon Penney is an Associate Professor in the Faculty of Education at Memorial University, a certified teacher and registered psychologist with the Newfoundland and Labrador Psychology Board. Her research is focused on special education, autism spectrum disorders, home and school partnerships as well as positive mental health. Email: scpenney@mun.ca

\section{Jacqueline Specht is a} Professor in the Faculty of Education at Western University in London Ontario where she is the director of the Canadian Research Centre on Inclusive Education. Her research expertise is in the areas of inclusive education, teacher development, and psychosocial aspects of individuals with disabilities. Email: jspecht@uwo.ca décrivons les problèmes auxquels les revues font face aujourd'hui ainsi que nos projets pour résoudre ces problèmes et maintenir une revue au $21^{\mathrm{e}}$ siècle.

Mots clés Revues académiques; Dialogue; Exceptionalités; Éducation inclusive; Direction d'une revue

\section{The editorship of the journal over the years}

In 1991, while at the University of Calgary, Judy Lupart founded the journal Exceptionality Education Canada (EEC), where she served as editor from 1991 to 1997. Vianne Timmons assumed the role of editor from 1997 to 2005 , and the EEC moved its publication base to the University of Prince Edward Island, as the place of publication had to be situated at the university of the editor. In 2005, the EEC returned to the editorship of Lupart who was now at the University of Alberta, where the journal was housed until 2014. During that time, Christina Rinaldi assumed the editorship (2009-2014), the journal name was changed to Exceptionality Education International (EEI), and it became an exclusively online journal. As workload was becoming an issue, associate editors were introduced to the editorial team. Donna McGhie-Richmond and Jess Whitley played important roles in managing the publication. It was clear that a succession plan was needed, and in 2014, the journal found a permanent home within the Canadian Research Centre on Inclusive Education at Western University. Tim Loreman and Jacqueline Specht became the editors, with Gabrielle Young and Sharon Penney assuming the roles of associate editors. The plan was to have people move through the roles. With the exit of Loreman in 2015, Young moved into the role of editor and Jenn de Lugt became an associate editor. As the journal is online, it can continue to be housed within the centre and editors and associate editors can come from across Canada. We thank the previous editors for their recollections and comments, which have added greatly to this historical look at EEI.

\section{Rationale for the development of the journal}

Lupart, Timmons, McGhie-Richmond, Whitley, and Loreman were asked to describe the history of the journal, and they noted that $E E C$ was developed because there was no journal at the time that looked at the education of students with special education needs in Canada. As Canada has a provincial education system, it was difficult to know what was happening across the country. Lupart saw the need to create a space where Canadian scholars could present their work. Lupart and Rinaldi believed that a unique aspect of the journal was the opportunity for guest editors to work on special issues related to specific concerns in the education field in Canada. Loreman commented that even with the move to an international audience, it is still the place for Canadian researchers working in inclusive education to publish their work. Timmons indicated that the journal was definitely a catalyst in bringing together the scholarly community, not only in publishing but also at the annual meeting of the Canadian Society for the Study of Education, both through talks by editors and authors and through the book award provided jointly with the Canadian Association for Educational Psychology.

\section{Changes to the education of students with exceptionalities in Canada}

Over the course of the last century, the history of service provision for children with exceptional needs has revealed substantial growth and development (Andrews \& Lupart, 1993). In 1975, the Education for All Handicapped Children Act, Public Law 94-142, was passed in the United States, ensuring an appropriate and free education for

Young, Gabrielle, de Lugt, Jenn, Penny, Sharon, Specht, Jacqueline. (2019). Exceptionality Education International: Responding to Change and Promoting Dialogue on Inclusive Education for All. Scholarly and Research Communication, 10(2): 1001307, 8 pp. 
all children, regardless of ability or disability status. In Canada, the adoption of the Charter of Rights and Freedoms in 1982 (Canadian Charter, 1982) spurred a call to action. International undertakings, including the United Nations Convention on the Rights of Persons with Disabilities (Article 24) (UNESCO, 2006), support this call to action. There has been a move from special education - an educational delivery system for students with exceptional learning needs, characterized by features such as: "categorization, specialized testing and assessment, special class placement, specially trained teachers, separate funding, and specialized teaching methods and curriculum" (Lupart, 2012, p. 3) - to integration, mainstreaming, and inclusion, in an attempt to "reverse the pattern of categorization and removal of students with exceptionalities" from participating in all aspects of learning and school participation with grade-level peers (Lupart, 2012, p. 4).

In 1994, the United Nations Educational, Scientific and Cultural Organization (UNESCO, 1994) Salamanca Statement and Framework for Action was instrumental in propelling the international community toward inclusive education by mandating a need to include all learners in a setting where differences are celebrated and individual needs are met. Furthermore, according to UNESCO (2005):

Inclusion is seen as a process of addressing and responding to the diversity of needs of all learners through increasing participation in learning, cultures and communities, and reducing exclusion within and from education. It involves changes and modifications in content, approaches, structures and strategies, with a common vision which covers all children of the appropriate age range and a conviction that it is the responsibility of the regular system to educate all children. (p. 13)

Spurring the move toward inclusion is the recognition that special education is not the most effective way to educate students who have learning challenges (Zigmond, Kloo, \& Volonino, 2009). Reviews of the literature acknowledge that it is more beneficial for students with exceptionalities to be educated in inclusive classrooms (Lindsay, 2007; Ruijs \& Peetsma, 2009). Students with exceptionalities perform better academically and have better social outcomes when included with other students, and the same is true for students without exceptionalities (Timmons \& Wagner, 2008).

There have been changes in the types of manuscripts submitted to the journal over the years, reflecting this change in thinking. Lupart noted that the articles in 1991 were more specific to the labels of children (e.g., developmental disability, learning disability, gifted). Timmons noted articles started focusing more broadly on what was happening across the country in special education. The tenure of her editorship (1997-2005) was at the height of the debate of inclusion across Canada. Rinaldi indicated that topics began to expand more broadly into issues pertaining to inclusion.

One change in educational policy is the notion that inclusion encompasses more than students with exceptional learning needs. Instead, it is being generally understood as student diversity (Loreman, Forlin, Chambers, Sharma, \& Deppeler, 2014), which encompasses differences in ability, culture, language, race, gender, and sexual orientation. In order to reflect changes to the education of students with exceptionalities in

Young, Gabrielle, de Lugt, Jenn, Penny, Sharon, Specht, Jacqueline. (2019). Exceptionality Education International: Responding to Change and Promoting Dialogue on Inclusive Education for All. Scholarly and Research Communication, 10(2): 1001307, 8 pp. 


\section{Scholarly and Research}

\section{Communication}

VOLUME 10 / ISSUE 2 / 2019
Canada, and in order to expand this dialogue, the purpose of the journal shifted from focusing on students with exceptionalities to addressing research related more broadly to inclusion for all students. This shift coincided with its move to the Canadian Research Centre on Inclusive Education. Loreman was instrumental in changing the focus of the EEI to align with this evolved conception of inclusion.

\section{The current status of the journal}

Exceptionality Education International currently provides a forum for research and dialogue on topics relevant to the education of all people, including how barriers to their full participation in education can be reduced or removed. While this broader view of inclusion has been slow to be adopted, we recognize people with exceptionalities are those from groups who have been traditionally marginalized in education as the result of ability, culture, ethnicity, gender, identity, language, religion, sexual orientation, and socioeconomic status. As a journal, we have changed our focus from students with special education needs to a broader focus of inclusion that supports all students - not solely those with identified disabilities - and publish on topics including but not limited to pedagogy, school and system organization and management, curricula, policy, inclusion, marginalization, international and national trends, classroom practice, adult education, educational innovations and initiatives, and teacher education.

\section{Focusing on inclusivity}

Inclusion is "based on the assertion of the same right to a quality education within their communities for all learners" (UNESCO, 1999, p. 21). Since the issuance of the Salamanca Statement (UNESCO, 1994), governments globally have increasingly focused on the development of inclusive education systems. As a result of this growing commitment to inclusion, classroom populations are becoming increasingly diverse. As practice changes, so too does the research literature addressing the issue.

Research demonstrates that the practice of inclusive education provides the most beneficial environment and outcomes for all students. Research reports that: a) there are no adverse effects or differences in the achievement of typically developing peers when students with diverse learning needs are educated in the regular classroom (Kalambouka, Farrell, Dyson, \& Kaplan, 2007); b) the inclusive classroom environment is more positive (or no different) than segregated settings for students with learning disabilities, intellectual disabilities, and language impairments (Canadian Council on Learning, 2009); and c) children who are educated in highly inclusive settings are in better health, enjoy going to school more, progress more quickly in school, and interact more positively with peers compared to students educated in minimally inclusive settings (Timmons \& Wagner, 2008).

In The Irregular School: Exclusion, Schooling and Inclusive Education (Slee, 2011), inclusion and exclusion are not treated as topics for dispassionate, intellectual engagement. Rather, Roger Slee asks readers to reflect upon their own values, actions, and contributions, and encourages us to be accountable for personal actions and values, and to recognize and accept our collective responsibility. Slee (2011) uses the term "collective indifference" (p. 21) to refer to the ability among those who are not "suffering" to regularly ignore those who are. As editors of the EEI, we recognize that we have everything

Young, Gabrielle, de Lugt, Jenn, Penny, Sharon, Specht, Jacqueline. (2019). Exceptionality Education International: Responding to Change and Promoting Dialogue on Inclusive Education for All. Scholarly and Research Communication, 10(2): 1001307, 8 pp. 
to gain from the authentic representation of diversity, as the improvements required in curriculum, pedagogy, assessment, school design, and the establishment of engaging learning communities is good for all students and educators (Slee, 2013). As editors we encourage authors and readers to examine our "collective indifference." Exclusion and inclusion raises fundamental questions surrounding unequal power relations. Exceptionality Education International provides a venue for addressing questions such as, "Who is in, who is out, and why?" And, perhaps more importantly, "What are we going to do about it?"

\section{Concerns experienced by journals}

Perhaps similar to many other journals, EEI continues to face challenges in securing reviewers. As editors, we work collaboratively and engage in dialogue to address pressing issues or concerns. Challenges are viewed as obstacles that can be overcome with a little creative thinking. One option that was proposed was moving toward a scientific model, whereby authors would submit a list of potential reviewers, with whom they have not collaborated, as possible candidates for the blind review process. Authors know and have cited the key researchers in their field, and as such, they are well situated to recommend new reviewers to include in our database. Inclusive education is a diverse field, with manuscripts needing to reflect cultural sensitivities in measuring inclusive education. Manuscripts must also reflect diverse areas of study, including issues pertaining to policy, resourcing, teacher preparation, leadership, teaching practices, and conceptualizing and measuring inclusive education in practice. While our editorial review board, consisting of internationally renowned scholars, is able to recommend potential reviewers, additional reviewers recommended by the authors may help editors to provide timely feedback. Furthermore, it is difficult for editors to gauge when full issues will be published online. We have managed this concern by publishing individual articles as they are accepted. The issue is closed once it reaches six to seven articles. An exception to this process is when there is a special theme issue, as the guest editor has secured specific reviewers long before the articles are ready for submission. The special issue is then published as a single issue with an introduction by the editor.

As with many other forms of knowledge sharing, operational costs continue to be at the forefront of conversations, especially during times of austerity when academic institutions consider cost-savings measures, such as the need for access to specific journals or access to specific publishing houses, and what this means for students requesting access to material in alignment with course content, independent research, and requisite learning. The move to an online journal in 2007 was the first step to streamline costs. Under Rinaldi, this model created substantial savings, which has allowed the journal to maintain a reasonable subscription rate. With a push toward open source publication, where the general public can access material online without cost, further concerns about financial sustainability emerged. In 2017, 16 percent of peer-reviewed articles worldwide were published in fully open access journals (SCImago, 2018). It has been debated whether open access can produce scientific excellence; however, in 2017, four of the 20 largest publishers were full open access publishers, and 16 were traditional subscription publishers with a range of subscription, hybrid, and fully open access journals (Curno \& Oeben, 2018). Over a three-year period (2015-2017), open access journals received on average seven percent more citations than subscription

Young, Gabrielle, de Lugt, Jenn, Penny, Sharon, Specht, Jacqueline. (2019). Exceptionality Education International: Responding to Change and Promoting Dialogue on Inclusive Education for All. Scholarly and Research Communication, 10(2): 1001307, 8 pp. 


\section{Scholarly and Research}

Communication

VOLUME 10 / ISSUE 2 / 2019 journals, and open access journals published by traditional subscription publishers are generally achieving more impact within the same publisher (Curno \& Oeben, 2018). Open access journals have a citation advantage, with an average of 2.9 citations per article for open access journals, versus 2.7 citations per article for subscription journals, including hybrids (Curno \& Oeben, 2018). These findings are supported by a White Paper by Springer Nature and Digital Science (2018) that outlined a citation advantage for open access articles over paywalled articles in hybrid subscription journals, as articles published in the open access format were 1.6 times more cited than paywalled articles within the same journals.

Funding agencies encourage academics to publish in open source publications, as public access to scientific knowledge contributes to accelerated discovery, innovation, and economic growth, and there is now evidence that open access journals outperform traditional subscription journals on citation metrics and deliver better impact for authors (Curno \& Oeben, 2018). While we are philosophically in support of open source publication, acknowledging the benefits in regards to knowledge sharing, there are concerns regarding sustainability, and what this means for journals that have ongoing operational costs, such as Web maintenance, communications, and, perhaps more importantly, ongoing editorial support from the time a manuscript is accepted through to its final publication online. Manuscripts published through the EEI are available through subscription during the first year post publication, and become publically accessible thereafter through the journal website. This supports public access and knowledge sharing, while securing the necessary funds for sustainability. Loreman raised the issue that graduate students and new scholars may not have grant money to support publications if there are costs associated with doing so. As a journal, we have always been committed to supporting new scholars. Our decision to have a one-year subscription helps to sustain the journal and continues to maintain a publication venue for scholars in the field of inclusive education, while ensuring the knowledge and expertise shared by authors and reviewers can be accessed by all.

As editors, we continue to work collaboratively, and while we should not underestimate the time required to provide service to this role, we are motivated to continue to serve in this capacity for we see value in what we do. Exceptionality Education International is unique in that we offer a venue for articles that are non-categorical in nature. Unlike other journals, which fall in the realm of special education and pertain specifically to students with autism, intellectual disabilities, specific learning disorders, and behavioural and emotional disorders, or students who are gifted, we focus on a broader conception of inclusion. Exceptionality Education International recognizes the need to support all forms of diversity, and accepts manuscripts related to and informing the teaching and learning of students in inclusive learning environments. We strive to support both novice and experienced scholars with the peer-review process, and we provide authors with constructive feedback to develop their manuscript into a publishable draft, either with our journal or another. Predatory journals exist, and the lure of an online publication with quick turnaround times may be appealing; however, there is credibility in the peer-review process. While the review process can be less than timely, and revisions may be arduous, the insight gathered from respected colleagues in the field, and the impact their feedback can have on a revised manuscript, is

Young, Gabrielle, de Lugt, Jenn, Penny, Sharon, Specht, Jacqueline. (2019). Exceptionality Education International: Responding to Change and Promoting Dialogue on Inclusive Education for All. Scholarly and Research Communication, 10(2): 1001307, 8 pp. 
invaluable. That is why we continue doing what we do - to serve the profession, advance knowledge that has been critiqued by experts in the field, and ensure credible research pertaining to students with exceptionalities in inclusive learning environments can be accessed by educators, administrators, and policymakers to inform policies and programming.

\section{Websites}

Canadian Association for Educational Psychology, https://csse-scee.ca/associations/caep-acp/\# Canadian Research Centre on Inclusive Education, https://www.inclusiveeducationresearch.ca/ Canadian Society for the Study of Education, https://csse-scee.ca/

\section{References}

Andrews, Jac, \& Lupart, Judy, L. (1993). The inclusive classroom: Educating exceptional children. Toronto, ON: Nelson.

Canadian Charter of Rights and Freedoms. (1982). s 15, Part I of the Constitution Act, 1982, being Schedule B to the Canada Act 1982 (UK), 1982, c11. URL: https://laws-lois.justice.gc.ca/eng /Const/page-15.html [February 14, 2019].

Canadian Council on Learning. (2009). Does placement matter? Comparing the academic performance of students with special needs in inclusive and separate settings. Lessons in learning. Canada Council on Learning. URL: https://files.eric.ed.gov/fulltext/ED519296.pdf [February 14, 2019].

Curno, Mirjam, \& Oeben, Stephanie. (2018). Scientific excellence at scale: Open access journals have a clear citation advantage over subscription journals [Blog post]. Frontiers. URL: https://blog .frontiersin.org/2018/07/11/scientific-excellence-at-scale-open-access-journals-have-a-clear -citation-advantage-over-subscription-journals/?utm_source=F-NLT\&utm_medium=EMLF \&utm_campaign=CCO_CORPO_20180700_scimago-blog [February 14, 2019].

Education for All Handicapped Children Act of 1975. (1975). Public Law No. 94-142. URL: https:// www.gpo.gov/fdsys/pkg/STATUTE-89/pdf/STATUTE-89-Pg773.pdf [February 14, 2019].

Kalambouka, Alfroditi, Farrell, Peter, Dyson, Alan, \& Kaplan, Ian. (2007). The impact of placing pupils with special educational needs in mainstream schools on the achievement of their peers.

Educational Research, 49(4), 365-382. doi: 10.1080/00131880701717222

Lindsay, Geoff. (2007). Educational psychology and the effectiveness of inclusive education/mainstreaming. British Journal of Educational Psychology, 77(1), 1-24. doi: 10.1348/000709906X156881

Loreman, Timothy, J., Forlin, Chris, Chambers, Dianne, Sharma, Umesh, \& Deppeler, Joanne. (2014). Conceptualizing and measuring inclusive education. In C. Forlin, \& T. Loreman. Measuring inclusive education: International perspectives on inclusive education, Vol. 3 (pp. 3-17). Bingley, UK: Emerald Group Publishing Ltd. doi:10.1108/S1479-363620140000003015

Lupart, Judy. (2012). Toward a unified system of education: Where do we go from here? Exceptionality Education International, 22(2), 3-7. URL: https://ir.lib.uwo.ca/eei/vol22/iss2/3 [February 14, 2019].

Ruijs, Nlenke, M., \& Peetsma, Thea. T. D. (2009). Effects of inclusion on students with and without special education needs reviewed. Educational Research Review, 4(2), 67-79.

SCImago. (2018). SJR - SCImago journal rank. SCImago. URL: http://www.scimagojr.com [February $14,2019]$.

Slee, Roger. (2011). The irregular school: Exclusion, schooling and inclusive education. London, UK: Routledge.

Slee, Roger. (2013). How do we make inclusive education happen when exclusion is a political predisposition? International Journal of Inclusive Education, 17(8), 895-907. doi: 10.1080/13603116

.2011 .602534

Young, Gabrielle, de Lugt, Jenn, Penny, Sharon, Specht, Jacqueline. (2019). Exceptionality Education International: Responding to Change and Promoting Dialogue on Inclusive Education for All. Scholarly and Research Communication, 10(2): 1001307, 8 pp.

\section{Scholarly and Research}

VOLUME 10 / ISSUE 2 / 2019 


\section{Scholarly and Research}

\section{Communication}

VOLUME 10 / ISSUE 2 / 2019
Springer Nature. (2018). Assessing the open access effect for hybrid journals. Springer Nature. URL: https://www.springernature.com/gp/open-research/about/oa-effect-hybrid [February 14, 2019].

Timmons, Vianne, \& Wagner, Maryam. (2008). Inclusive education knowledge exchange initiative: An analysis of the Statistics Canada Participation and Activity Limitation Survey. URL: http://en .copian.ca/library/research/ccl/inclusive_edu_know/inclusive_edu_know.pdf [February 14, 2019].

United Nations Educational, Scientific and Cultural Organization. (1994). The Salamanca statement and framework for action on special needs education. Paris, FR: UNESCO. URL: http://www .unesco.org/education/pdf/SALAMA_E.PDF [February 14, 2019].

United Nations Educational, Scientific and Cultural Organization. (1999). Salamanca five years on: A review of UNESCO activities in the light of The Salamanca Statement and Framework for Action. Paris, FR: UNESCO. URL: http://unesdoc.unesco.org/images/o011/oo1181/118118eo.pdf [February 14, 2019].

United Nations Educational, Scientific and Cultural Organization. (2005). Guidelines for inclusion: Ensuring access to education for all. Paris, FR: UNESCO. URL: http://unesdoc.unesco.org /images/0014/001402/140224e.pdf [February 14, 2019].

United Nations Educational, Scientific and Cultural Organization. (2006). Convention on the Rights of Persons with Disabilities (CRPD) Article 24 - Education. New York, NY: UNESCO. URL: https://www.un.org/development/desa/disabilities/convention-on-the-rights-of-persons-withdisabilities/article-24-education.html [February 14, 2019].

Zigmond, Naomi, Kloo, Amanda, \& Volonino, Victoria. (2009). What, where, and how? Special education in the climate of full inclusion. Exceptionality, 17(4), 189-204. 